\title{
VENTRICULAR SEPTAL DEFECT IN EARLY CHILDHOOD
}

\author{
BY \\ R. M. MARQUIS * \\ From the Royal Infirmary, Edinburgh \\ Received November 25, 1949.
}

A particular group of children in whom a defect of the ventricular septum leads to cardiac disability in early life is the subject of this paper. The clinical picture that serves to distinguish the graver disability from the better known maladie de Roger is outlined.

\section{The Maladie de Roger-Clinical Features}

The maladie de Roger has been a well-recognized clinical entity since the characteristic parasternal murmur was first described (Roger, 1879). The absence of symptoms and the presence of striking physical signs have been taken as the essential points in the diagnosis (Muir and Brown, 1934). In the routine examination of school children, follow-up studies have confirmed the clinical impression that the isolated ventricular septal defect may be regarded as a benign lesion. As with Roger's original cases, repeated examination has revealed no clinical deterioration and no change in the physical signs. Commonly there is no significant radiological or electrocardiographic alteration during the school period (Perry, 1937). Such patients may lead useful, energetic lives and, provided they escape subacute bacterial endocarditis and other incidental diseases, die of congestive heart failure in middle or later life. Roger's oldest case was a woman of 50 years who had borne four children and was leading an unrestricted life; cases recognized as having congenital heart disease in infancy have been followed to over 70 years of age (Gilchrist, 1948).

\section{The Ventricular Septal Defect-Autopsy Features}

Pathological confirmation in the maladie de Roger is rare. Roger's contribution to medicine is all the more remarkable in that he did not have the opportunity to confirm the diagnosis in any one of his cases. None of Muir and Brown's (1934) cases had autopsy confirmation, and only two of Perry's cases had died at the time he gave his paper (1937). The first case diagnosed clinically to be proved post-mortem was a boy of 4 years who died from diphtheria (Dupré, 1891). The defect usually occurs through the muscular septum just anterior to the membranous septum. It is circular or oval in shape and its margins are surrounded by fibrous tissue. It opens into the right ventricle behind the septal cusp of the tricuspid valve. The size of the defect varies from a minute opening to $1 \mathrm{~cm}$. in its longest diameter (Abbott, 1936; Brown, 1939).

In sharp contrast to the benign clinical picture of the symptomless lesion, post-mortem statistics show that the ventricular septal defect alone, or in combination with some other minor flaw, has in fact a high mortality in infancy and early childhood. Of Abbott's 50 cases, no less than 21 died at or under 5 years of age (Bauer and Astbury, 1944). Of 110 consecutive cases of congenital heart disease coming to autopsy during the first three years of life in the Royal Hospital for Sick Children, Edinburgh, no less than $28(25 \%)$ had such defects of the ventricular septum. This malformation thus constituted the commonest single lesion in this post-mortem series.

* Kirk Duncanson Research Fellow of the Royal College of Physicians, Edinburgh. 
The malformation may be similar to that in the maladie de Roger, or there may be some relatively minor difference. The associated flaws, slight in themselves, take a variety of forms.

(1) Incompetence of the tricuspid valve through adherence of its septal cusp to the defect (Abbott, 1927; Muir and Brown, 1934).

(2) Incompetence of the aortic valve through involvement of the adjacent cusp in the defect (Laubry, Routier, and Soulié, 1933).

(3) The defect may be high, the aortic septum failing to meet the ventricular septum, and the blood from the high pressure left ventricle is pumped almost directly into the pulmonary artery.

(4) The defect may be larger than $1 \mathrm{~cm}$. in its longest diameter.

(5) The defect may be situated between the aortic valve and an anteriorly rotated mitral valve; this variation is occasionally associated with a partial subaortic stenosis (Taussig, 1947).

(6) The aorta may be slightly hypoplastic.

(7) The defect may replace the membranous septum (MacGregor, 1949).

The cause of death in the simplest cases is generally an incidental disease, such as gastro-enteritis, but in the particular group to which attention is directed, the malformation of the heart is itself responsible for death.

\section{CASE RECORDS}

Four cases are reported to illustrate the clinical features of this particular group in which the ventricular septal defect gives rise to considerable difficulties and may lead to death from congestive failure within the first few years of life. The presence of this malformation was confirmed postmortem in the first two cases.

Case 1. Female, aged $2 \frac{1}{2}$ years. Admitted to hospital in congestive heart failure. Walked at 14 months. Liable to respiratory infections; easily tired and breathless.

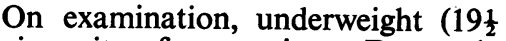
lb.) in spite of congestion. Dyspnœic at rest, prominent sternum, deep Harrison's sulci. Tachycardia, 140 a minute. B.P. 130/95. Gross cardiac enlargement. No thrills. Coarse, grating, systolic murmur, maximal in second and third intercostal spaces at left sternal margin. Pulmonary second sound grossly accentuated. Liver enlarged. Lungs congested, but no peripheral œdema. Tinge of cyanosis on admission cleared with rest.

Gross, generalized cardiac enlargement on radioscopy (Fig. 1) with congestion of pulmonary vessels. Highly unusual cardiogram (Fig. 2), typical of neither isolated right nor isolated left ventricular hypertrophy.

Temporary improvement followed by increasing dyspnœa and death. At necropsy immense cardiac enlargement (Fig. 3). Entire anterior surface occupied by right ventricle. Equal degree of hypertrophy and dilatation of both ventricles. Slight dilatation of right atrium, none of left. Left auricular

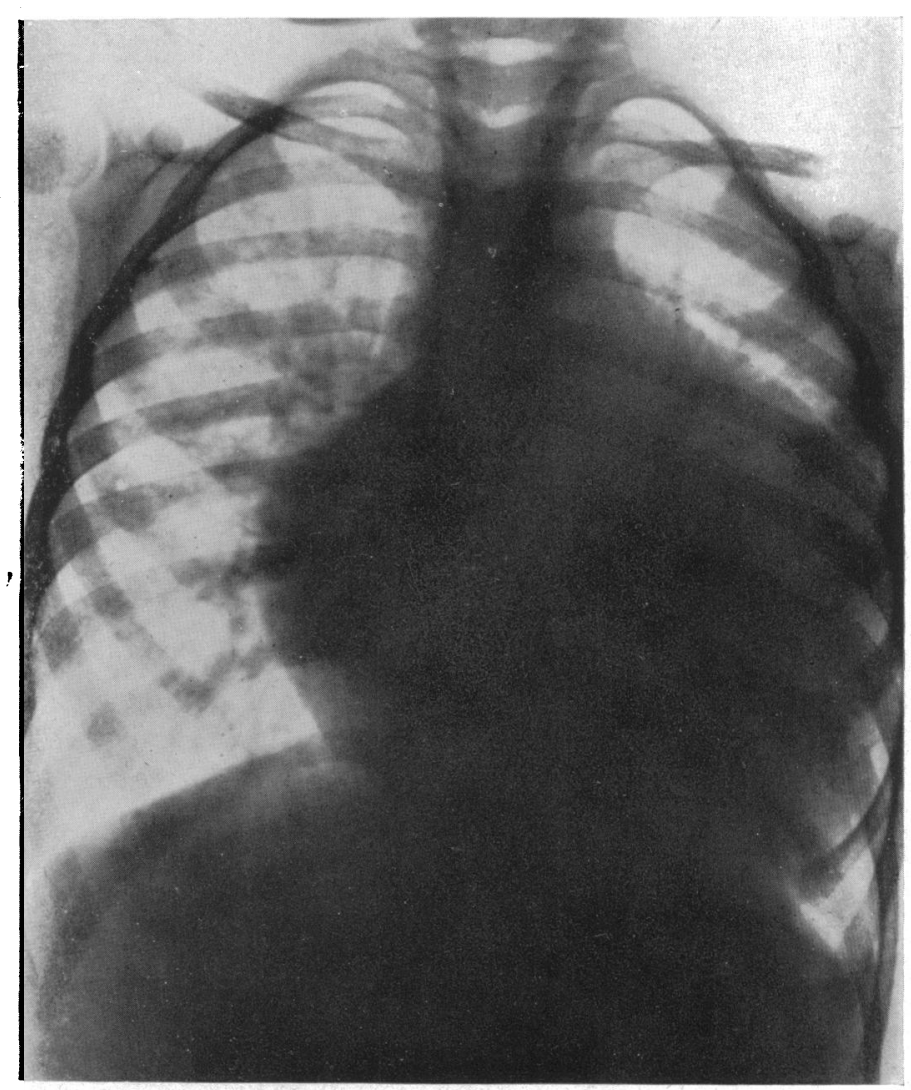

Fig. 1.-Radiograph (anterior) of Case 1 at two and a half years. Gross, generalized cardiac enlargement. Congested lung fields. 
appendage rotated anteriorly. Slight aortic hypoplasia. Pulmonary artery double the size of aorta. A large ventricular septal defect with fleshy margins replacing membranous septum and large part of anterior muscular septum; situated between aortic and anteriorly rotated mitral valve and $3 \mathrm{~cm}$. in its longest diameter. Chordæ of anterior mitral cusp originating from anterior margin of defect. Partial subaortic stenosis not apparent. All valves competent. Pulmonary congestion and commencing hypostatic pneumonia.

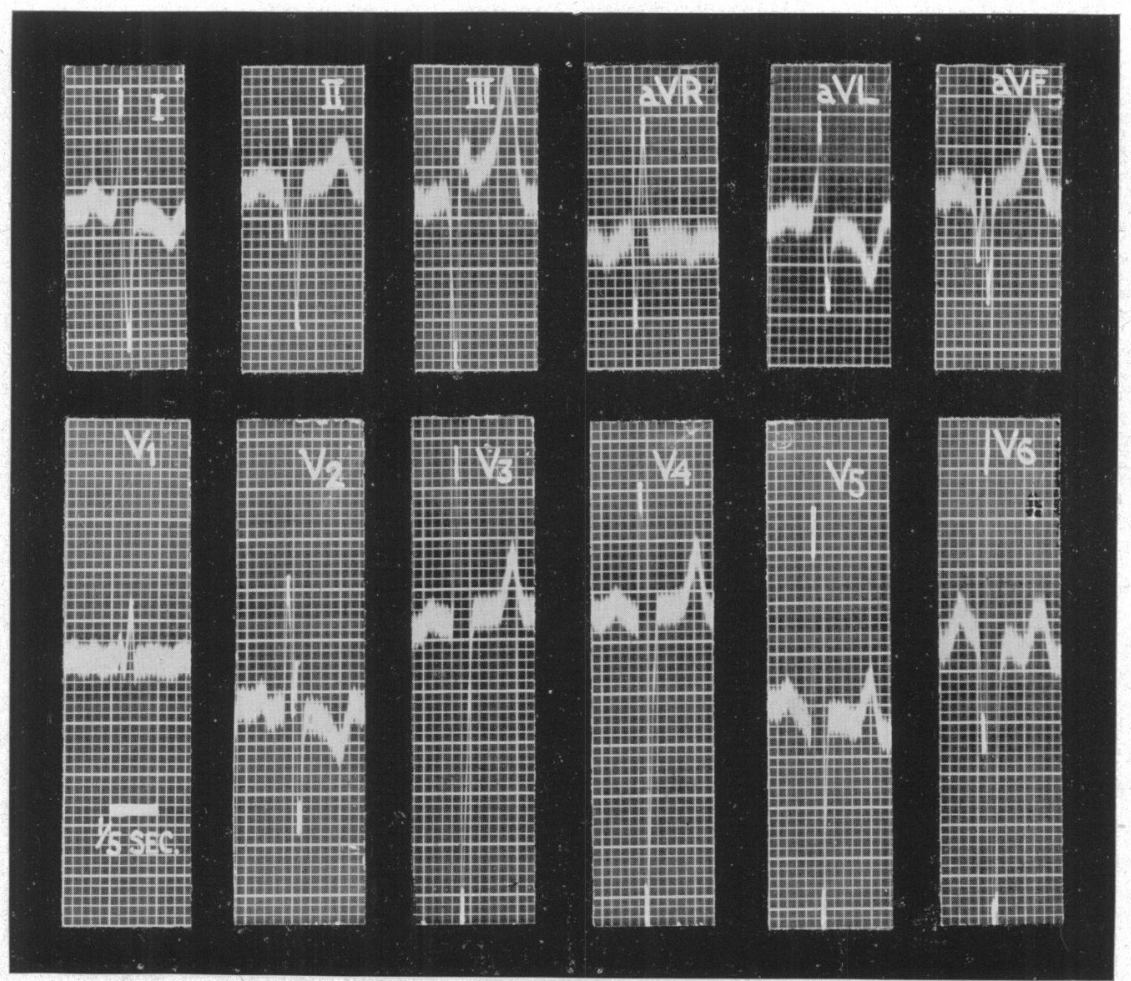

Fig. 2.-Electrocardiogram of Case 1 at two and a half years. Deep $\mathbf{S}$ wave in lead 1 ; notched $\mathbf{R}$ wave as sole initial deflection in V1, tall $R$ wave in aVR and deep $S$ wave in V6 are suggestive of right ventricular hypertrophy; deep $Q$ and tall $R$ wave in V6 is suggestive of left ventricular hypertrophy. (The peaks of the QRS complexes have been marked.)

Case 2. Female, aged 1 year. Admitted to hospital with acute pharyngitis and congestive heart failure. Dyspnœa on slightest exertion, recurrent respiratory infections and failure to thrive since 3 weeks of age. Never cyanosed. Increasing cardiac enlargement, pulmonary and hepatic congestion noted from 3 months of age. Radiological enlargement of both ventricles, pulmonary artery and hilar vessels with pulmonary congestion at 6 months of age (Fig. 4 and 5).

On examination at 1 year intense dyspnœa, underweight $(13 \mathrm{lb}$.), prominent sternum, deep Harrison's sulci. Tachycardia 140 a minute. Moderate pulse pressure. Gross cardiac enlargement, heaving apex beat and variable parasternal, systolic thrill. Widespread, coarse, systolic murmur maximal up left sternal margin. Grossly accentuated pulmonary second sound. Crepitations throughout both lungs, bronchial breathing at left base.

Increase in cardiac enlargement on radioscopy and collapse of left lower lobe of lung. Cardiogram showed right and left ventricular hypertrophy (Fig. 6).

Death on first birthday. At necropsy gross cardiac enlargement (Fig. 7), both ventricles hypertrophied, left much more than right. Aorta larger than normal but pulmonary artery nearly twice its size. All valves competent. Defect through membranous ventricular septum with soft fibrous margins, measuring $1 \mathrm{~cm}$. in its longest diameter and opening into the right ventricle beneath septal cusp of tricuspid valve.

Case 3. Male, aged $2 \frac{1}{2}$ years. Admitted for investigation. Recurrent respiratory infections since infancy, associated exertional dyspnœea. 
Fig. 3.-Drawing of heart from Case 1. Anterior cusp of mitral valve divided to show full extent of septal defect. Posterior wall of left atrium divided to show origin of aorta. Anterior rotation of left auricular appendage.

On examination, underweight ( $26 \frac{1}{2} \mathrm{lb}$.), deep Harrison's sulci and persistent tachycardia, 120 a minute. B.P. 102/70. No pulmonary or hepatic congestion. Marked cardiac enlargement. Systolic thrill down left sternal margin. Widespread, coarse, grating systolic murmur maximal in third interspace at left sternal margin. Pulmonary second sound accentuated.

On radioscopy considerable cardiac enlargement involving both ventricles (Fig. 8 and 9). Pulmonary artery enlarged and hilar vessels prominent. No hilar dance. Unusual cardiogram (Fig. 10) with left axis deviation but suggesting more hypertrophy of right than of left ventricle.

Clinical diagnosis was a large defect of the ventricular septum.

Case 4. Male, aged 13 months. Referred for investigation. Respiratory infection at 3 months of age. Subsequent recurrent episodes of pulmonary and hepatic congestion. Steady improvement with digitalis.

On examination grossly underweight $(13 \mathrm{lb}$.) in spite of excellent home. Prominent sternum. Deep Harrison's sulci. Tachycardia, 140 a minute. B.P. 86/54. Marked cardiac enlargement but no pulmonary or hepatic congestion. Variable, parasternal, systolic thrill. Widespread, loud, very coarse, systolic murmur maximal in third interspace at left sternal margin. Variable, soft, diastolic murmur at lower end sternum and towards apex. Accentuated pulmonary second sound.

On radioscopy enlargement of both ventricles (Fig. 11 and 12). Slight left atrial enlargement; enlarged, pulsatile pulmonary artery and prominent, non-expansile hilar vessels. Cardiogram (Fig. 13) left axis deviation but suggest ing hypertrophy of both ventricles in chest leads.

Clinical diagnosis was a large defect of ventricular septum. 


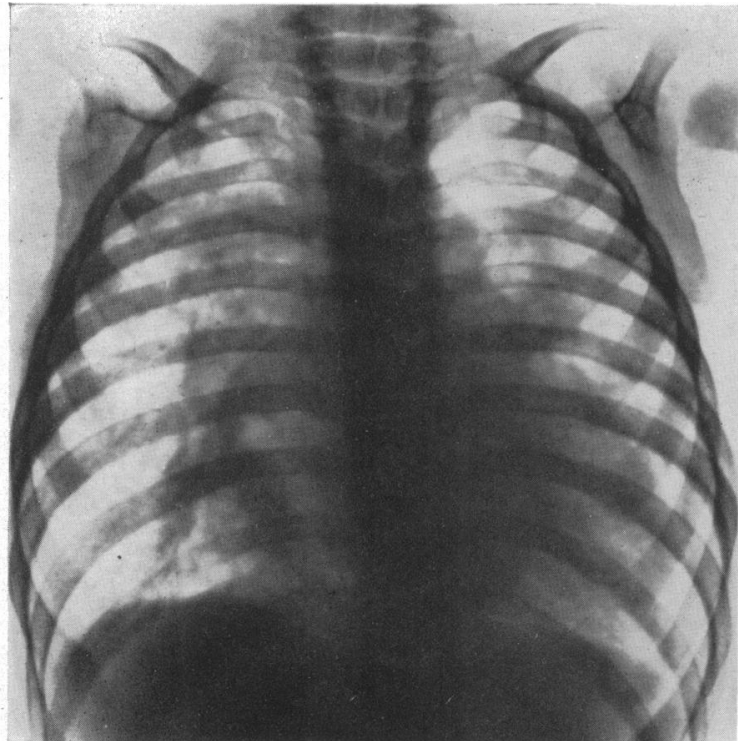

FIG. 4.-Radiograph (anterior) of Case 2 at 6 months. Generalized cardiac enlargement, enlarged pulmonary artery, prominent hilar vessels and pulmonary congestion.

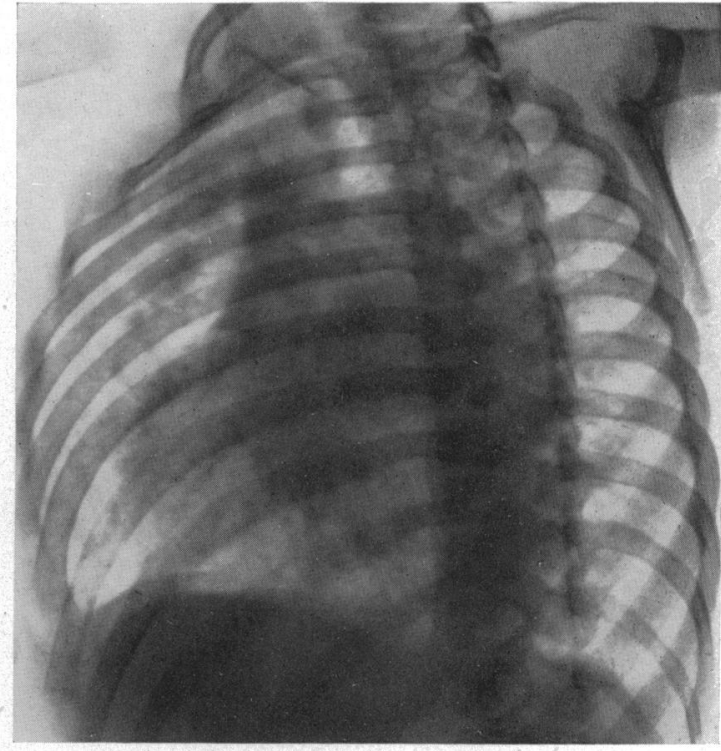

Fig. 5.-Radiograph (left anterior oblique) of Case 2 at 6 months. Enlargement of both ventricles.

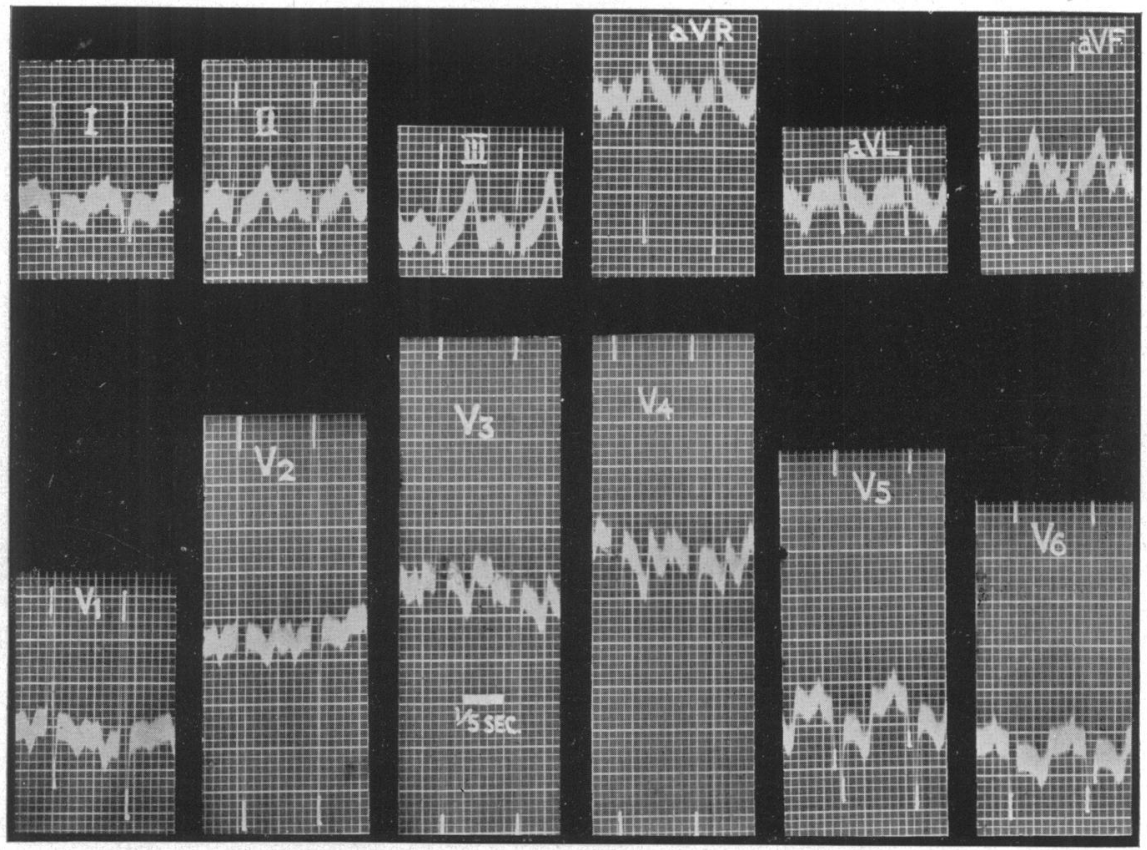

FIG. 6.-Electrocardiogram of Case 2 at 12 months. Tall $R$, moderate $S$ and inverted $T$ wave of right ventricular hypertrophy in $V 1$; deep $Q$, tall $R$ and inverted $T$ of left ventricular hypertrophy in V6. (The peaks of the QRS complexes have been marked.) 


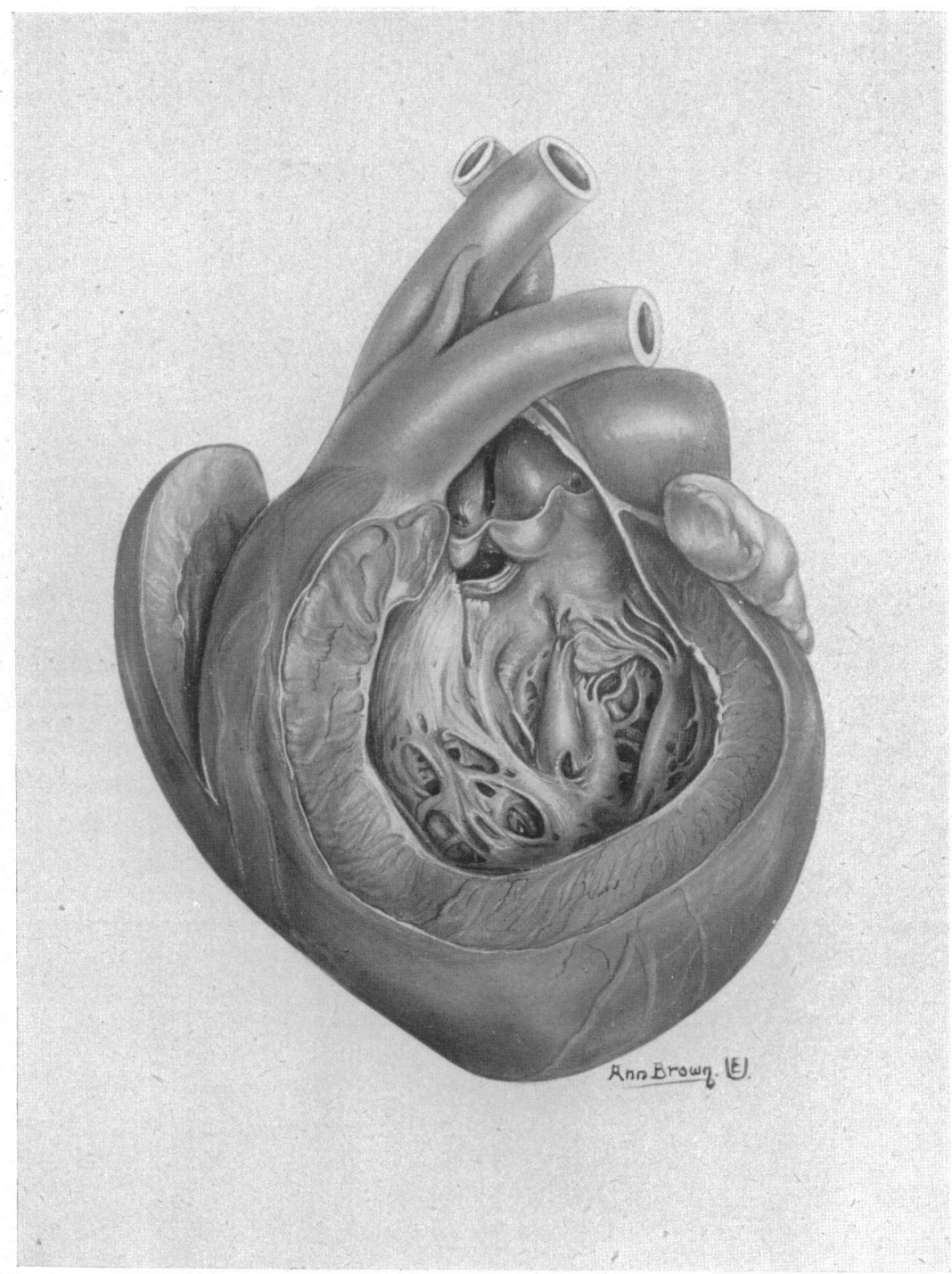

Fig. 7.-Drawing of heart from Case 2. Defect replaces the membranous septum.

\section{Summary of CASE Notes}

These four cases conform to a common clinical pattern of which the principal features are under-development of varying degree from an early age, an absence of cyanosis, a liability to respiratory infection, and a tendency to congestive heart failure in early childhood. There is gross cardiac enlargement, Roger's murmur, accentuation of the pulmonary second sound, and an occasional diastolic murmur down the left sternal margin. The pulse pressure tends to be small. Radiological examination shows the enlargement to involve both ventricles and the pulmonary artery. The hilar vessels are prominent. Electrocardiographic tracings suggest hypertrophy of both ventricles.

The main abnormality was a ventricular septal defect in Cases 1 and 2 and this was the clinical diagnosis in Cases 3 and 4 . Although the actual malformations were very different in the first two cases, the clinical pictures were comparable. 


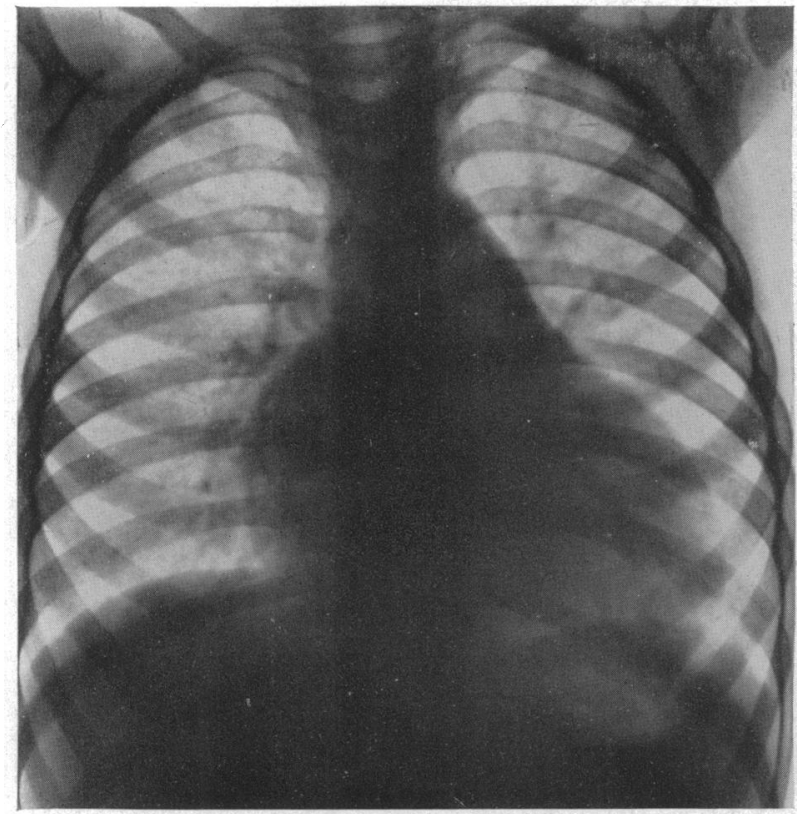

FIG. 8.-Radiograph (anterior) of Case 3 at two and a half years. Generalized cardiac enlargement, enlarged pulmonary artery and prominent hilar vessels.

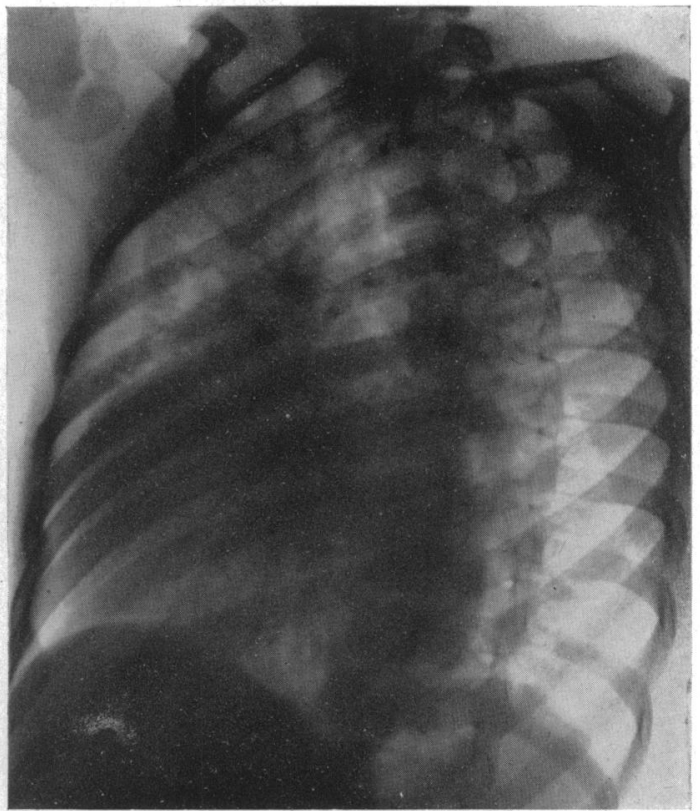

Fig. 9.-Radiograph (left anterior oblique) of Case 3 at two and a half years. Enlargement of both ventricles.

\section{DisCUSSION}

Respiratory infection. The clinical picture in this small group of children is thus very different from the maladie de Roger in its classical form. Under-development and respiratory infections are rare in Roger's disease during the school period (Muir and Brown, 1934), but it is interesting that Roger (1879) thought that his cases, most of whom were young children, had a predisposition to respiratory disease. He thought, moreover, that such infection aggravated the disorder of the circulation. Müller (1920), 3 of whose 9 cases died under 2 years of age, also stressed the danger of pulmonary infection. Laubry and Pezzi (1921) have pointed out that the relatively symptomless ventricular septal defect represents an equilibrium between the ventricles which they consider is all too frequently broken. Although the circulatory dynamics of this concept require experimental confirmation, it is suggested that in early childhood a respiratory infection may be the factor that breaks this equilibrium and thus initiates a train of events, as illustrated by the four cases reported above, which may lead to congestive failure and death. Respiratory infection was responsible for the death of at least 10 of Abbott's 21 cases dying under 5 years of age. It was a major factor in at least 9 of the 28 cases in the Edinburgh Children's Hospital series.

All four cases showed deformity of the chest with well-marked Harrison's sulci. This is secondary to the recurrent respiratory infections and a weak chest musculature in early life (Naish and Wallis, 1948). Similar chest deformity has been observed in all types of congenital heart disease in which both these factors are present.

Subacute bacterial endocarditis. Bacterial endocarditis is a well-recognized danger in Roger's disease, but is uncommon in early childhood. Over the age of two years Gelfman and Levine (1942) report it as the cause of death in 8 out of 14 cases $(57 \%)$. Under that age they report it in only 2 out of 30 cases $(7 \%)$. Of Abbott's 21 cases dying under five years of age bacterial endocarditis was the cause of death of only 2, and they were both over four years of age. None of the 28 cases in the Edinburgh Children's Hospital series showed evidence of bacterial endocarditis. 


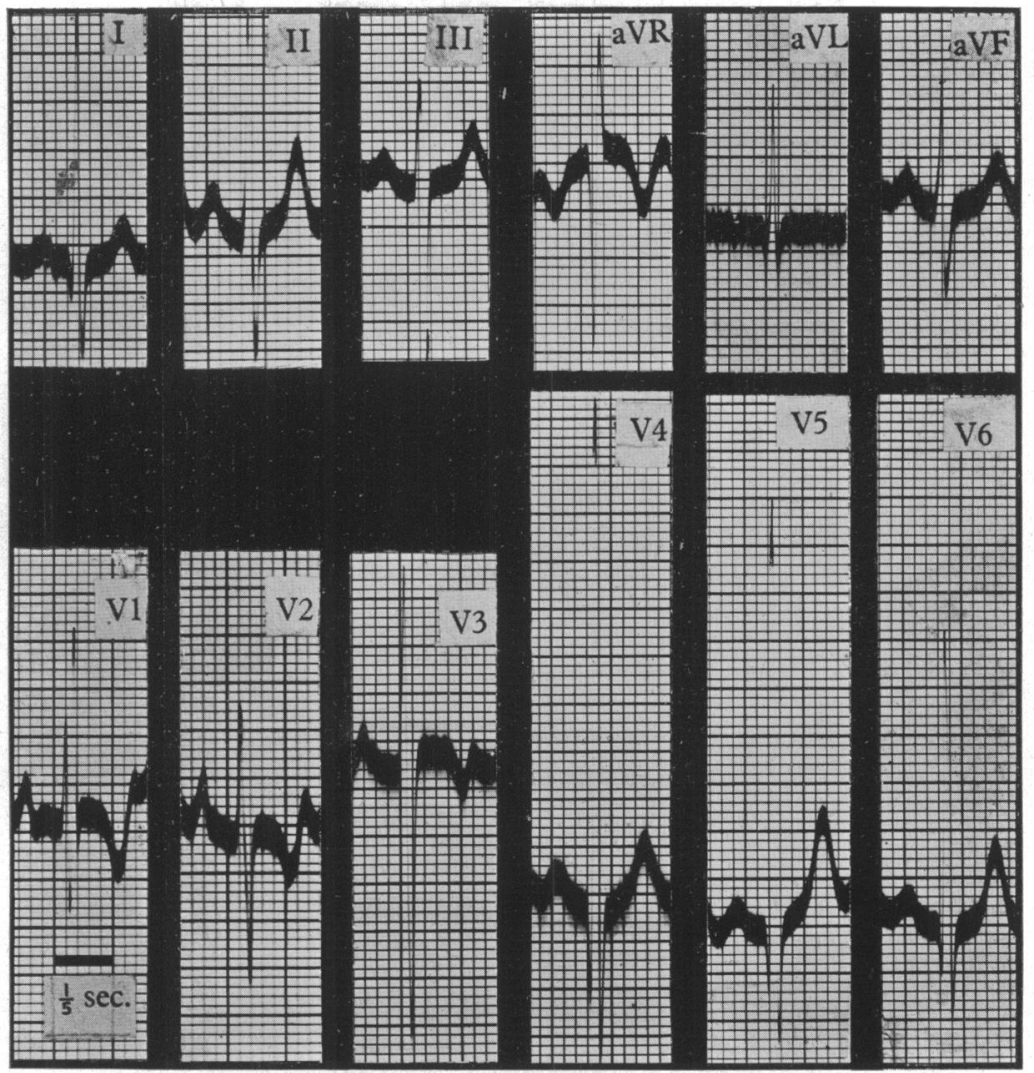

FIG. 10.-Electrocardiogram of Case 3 at two and a half years. Left axis deviation but deep $S$ in lead $I$; $R$ and $\mathbf{R}^{\prime}$ waves in V1 and height of $R$ wave in aVR are suggestive of right ventricular hypertrophy; tall $R$ wave in aVL and in V4 to V6 are suggestive of left ventricular hypertrophy.

Cardiovascular signs. In Roger's disease the shunt is small and there is little burden on the heart. The gross cardiac enlargement in the graver disability under discussion here is thought to be due to a greater flow of blood through the septal defect. This is especially liable to occur in the presence of associated anomalies such as aortic incompetence or when the defect is large. In spite of the increased volume of blood received by the right ventricle, the output of the two ventricles remains equal for the reason that the increased output of the right ventricle is passed through the lungs to the left side of the heart. The blood flow through the pulmonary artery is greater than that through the aorta as part of the left ventricular output forms the shunt to the right ventricle. There is thus an increased pulmonary blood flow, hypertrophy of both ventricles, enlargement of the pulmonary artery and relative depletion of the systemic circulation. As the pulmonary pressure rises, the right ventricle fails to clear its double intake and there is congestive failure with venous distension and liver engorgement.

The systolic murmur is no different from that described by Roger and there is no reason to suppose that it is not caused by the flow of blood through the defect. Accentuation of the pulmonary second sound was heard in all four cases. Such accentuation is a frequent finding in any lesion increasing the pressure in the pulmonary circulation. In older patients shown to have ventricular septal defects, catheterization of the pulmonary artery has demonstrated the increase of pressure in that vessel (Handelsman et al., 1948; Griswold et al., 1949; Burchell et al., 1948). In Case 4 there was also a diastolic murmur at the lower end of the sternum. Similar murmurs 


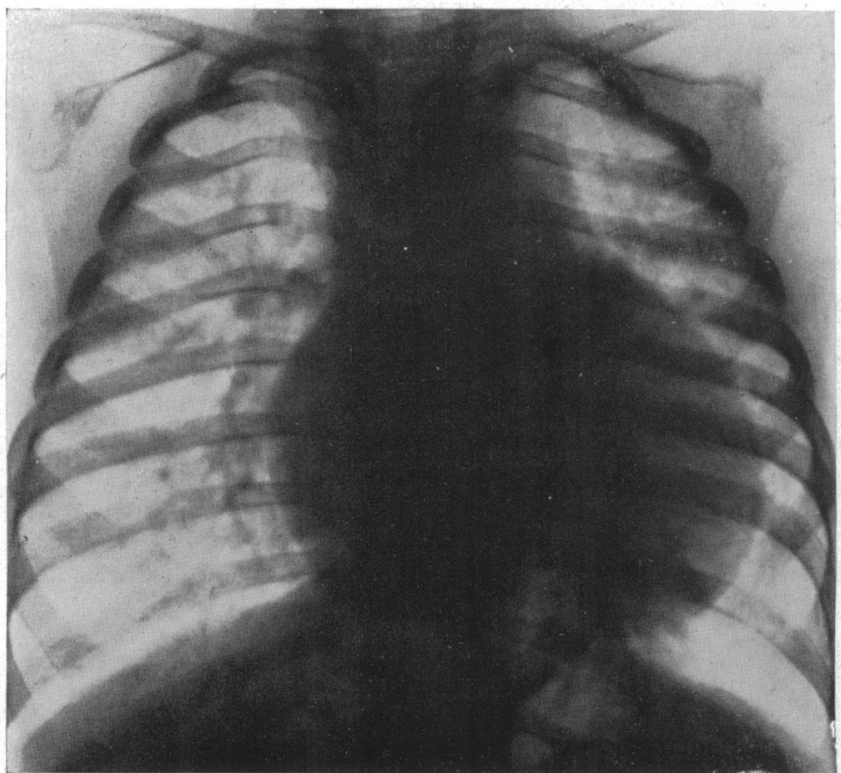

Fig 11.-Radiograph (anterior) of Case 4 at 10 months. Generalized cardiac enlargement and prominent hilar vessels.

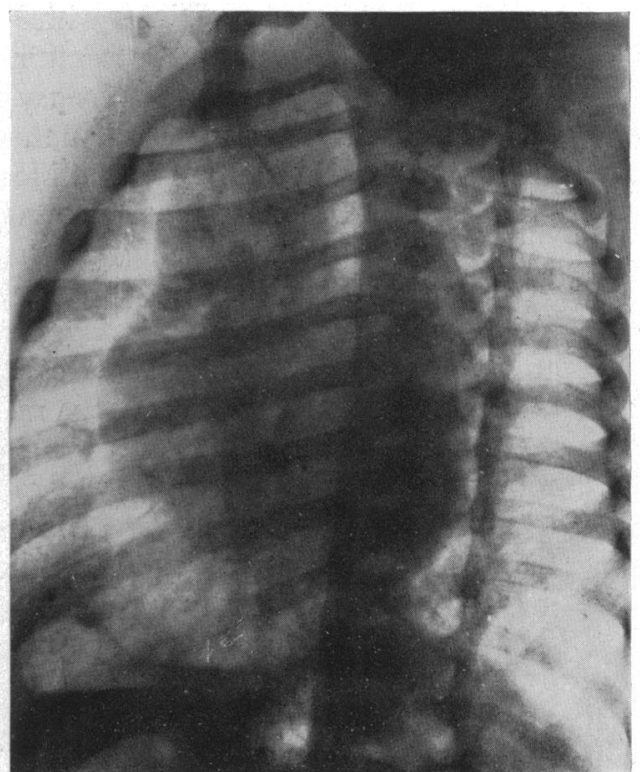

Fig. 12.-Radiograph (left anterior oblique) of Case 4 at 10 months. Enlargement of both ventricles.

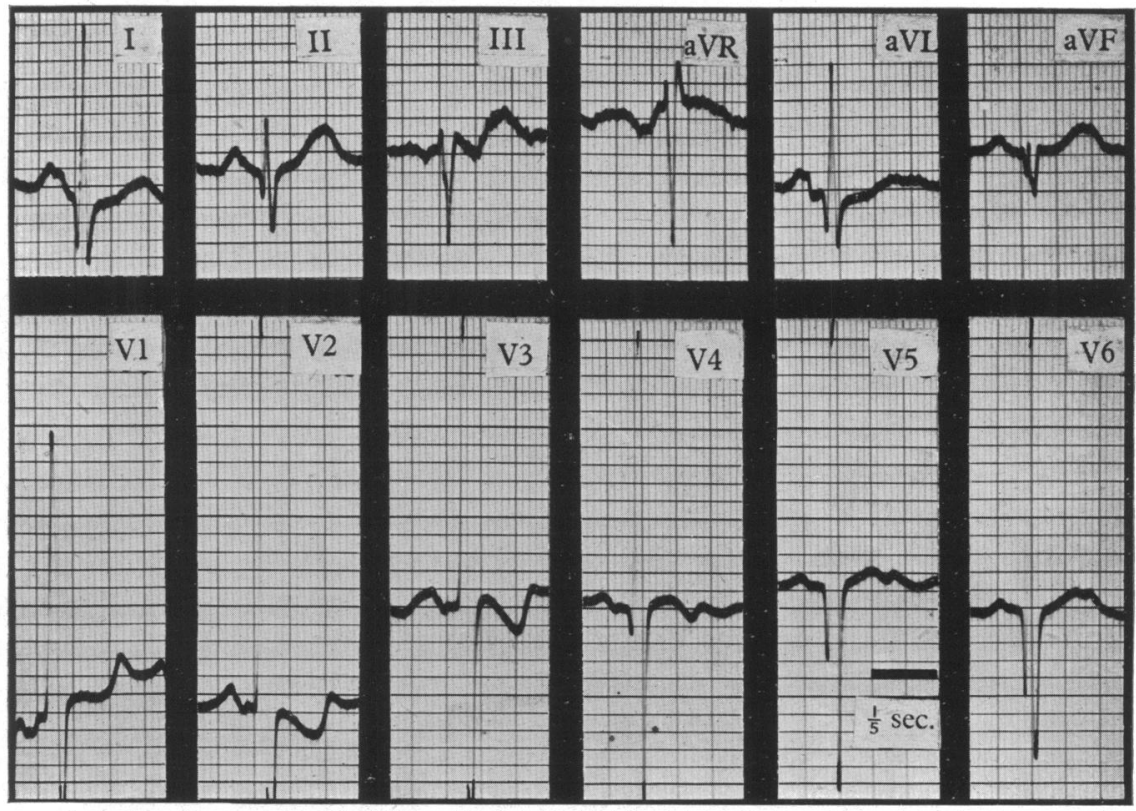

Fig. 13.-Electrocardiogram of Case 4 at 13 months. Left axis deviation but moderate $\mathbf{S}$ wave in lead I. Tall $\mathbf{R}$ wave in V1 is suggestive of right ventricular hypertrophy; deep Q, tall $R$ waves in V5 and V6, and tall $R$ wave in aVL are suggestive of left ventricular hypertrophy. 
have been noted in older patients with Roger's disease, in patients shown on catheterization to have large defects of the ventricular septum (Baldwin, Moore, and Noble, 1946; Handelsman et al., 1948), and in cases proved at necropsy to have isolated defects of the ventricular septum (Müller, 1920). This murmur is important in that its presence does not invalidate the diagnosis of ventricular septal defect. It is usually soft and blowing in character and best heard down the left sternal margin. Like the pulmonary second sound, it is thought to be due to the raised pulmonary pressure and thus similar to the Graham-Steell murmur in mitral stenosis. When one of the aortic cusps is involved in the defect, the diastolic murmur may be due to aortic incompetence (East, 1937).

Radiological and electrocardiographic features. In the young patient with Roger's disease radiological examination shows the cardiovascular shadow to be within normal limits. As age increases enlargement of both ventricles may become apparent and gross enlargement of the pulmonary artery has been seen. In such cases slight expansile pulsation may appear in the hilar shadows although it is never as obvious as that of the atrial septal defect. In contrast to this slowly developing picture, all four patients in this series showed enlargement of both ventricles and of the pulmonary artery from an early age. Although the hilar vessels were prominent, hilar dance was not seen in this age group.

The electrocardiogram is within normal limits until well on into adult life in the maladie de Roger. When changes do appear, they are those of left ventricular hypertrophy. This supports the contention that hypertrophy which increases the masses of both ventricles proportionately cannot be distinguished in the cardiogram from preponderant hypertrophy of the left ventricle (Wilson, Rosenbaum, and Johnston, 1947). In contrast, Case 2 showed cardiographic evidence of hypertrophy of both ventricles. This is all the more remarkable in that at autopsy the hypertrophy of the left ventricle was significantly greater than that of the right. In the other cases this double hypertrophy was not clearly shown in the unipolar chest leads. In the standard leads left axis deviation was usual, but the $S$ wave tended to be prominent in lead I. In the unipolar chest leads a tall $\mathrm{R}$ was the main initial deflection in $\mathrm{V} 1$ and a tall $\mathrm{R}$ was preceded by a deep $\mathrm{Q}$ in V6. Although inconclusive, these changes are suggestive of hypertrophy of both ventricles.

Differential diagnosis. An atrial septal defect may be the cause of great cardiac enlargement and recurrent respiratory infections in early life (Taussig, 1947), but on clinical examination the signs are usually less marked than those of the cases reported here. Moreover, the enlargement is confined to the right side of the heart and the radiological contour is characteristic. The electrocardiogram is within normal limits or shows the changes of isolated right ventricular hypertrophy or of partial or complete right bundle branch block. It is not yet known how early or how frequently the pattern of right bundle branch block develops in childhood, but with increasing experience of unipolar cardiography it is considered that the cardiogram will be of even greater assistance in distinguishing the ventricular from the atrial septal defect.

Post-mortem figures suggest that the recurrent respiratory infections in the atrial septal defect do not impose such a heavy burden on the heart as they do in the ventricular septal defect. Of the 110 cases in the Edinburgh Children's Hospital sêries, only one had a significant defect of the atrial septum as an isolated lesion. This supports the experience of clinical practice in which it has been estimated that 82 per cent of cases of atrial septal defect are not recognized until the age of 20 years has been attained (Gilchrist, 1945).

A patent ductus arteriosus is only rarely of sufficient size to cause gross cardiac enlargement in early life. In such cases there may be difficulty in distinguishing the disorder from that of the group of children under discussion. This is especially so when the ventricular septal defect is associated with a diastolic murmur. One of Müller's (1920) cases who had been diagnosed clinically as a patent ductus was found post-mortem to have an isolated defect of the ventricular septum. When the ventricular septal defect is associated with aortic incompetence the pulse pressure is large and the differential diagnosis from a patent ductus may be extremely difficult (Laubry, Routier, and Soulié, 1933); but in the former the diastolic murmur tends to be maximal down the left sternal border, and when the ductus is of sufficient size to lead to early failure, a true Gibson murmur, 
maximum below the inner third of the left clavicle, develops early. Radiologically prominence of the right ventricle in the left oblique view is uncommon in the patent ductus and the cardiogram is within normal limits or shows isolated left ventricular hypertrophy.

Prognosis. On the evidence of the four cases reported in this paper, the prognosis must be considered poor once this clinical picture has developed. Further experience may modify this view, but it is clear that the outlook does not compare with that of the classical form of Roger's disease.

It has been suggested that a ventricular septal defect, large and important in infancy, may, with the growth of the heart, become relatively smaller and of little consequence. The defect may ultimately become negligible and fail to give rise to physical signs (Brown 1939). The evidence for this is the disappearance of the systolic murmur and thrill as the child grows. The child is symptomless when the signs are present and remains so after their disappearance. It has not been suggested that a grossly disabled child later becomes symptomless. It is unlikely that such spontaneous closure of the defect can be hoped for in the clinical group described in this paper.

\section{SUMMARY}

Necropsy reports show that the ventricular septal defect has a high mortality rate in early childhood. The cause of death in this age group is usually incidental disease. Respiratory infection is particularly dangerous.

Attention is directed to a group of children in whom a ventricular septal defect is directly responsible for death. The main pathological variations of the group are listed.

The clinical features of under-development, recurrent respiratory infections, early congest ive heart failure, Roger's murmur, accentuation of the pulmonary second sound and an occasional diastolic murmur down the left sternal margin, represent the clinical picture of the ventricular septal defect in which the equilibrium between the ventricles has been broken in early childhood. It is suggested that this clinical picture is characteristic, irrespective of the factor responsible for the disturbance of equilibrium.

These views are supported by the clinical features in four cases, in the first two of which the presence of a ventricular septal defect was confirmed post-mortem.

The possible factors responsible for the development of the clinical features in this group are discussed and its differential diagnosis from the rarer cases of atrial septal defect and patent ductus arteriosus with disability in early life is considered.

The prognosis of the group appears to be poor.

\section{ADDENDUM}

Since the completion of this paper, Soulié, Routier, and Bernal (1949) have again directed attention to the difficulty that may be experienced in differentiating a ventricular septal defect with associated aortic incompetence from a patent ductus arteriosus. Selzer (1949) has stressed the frequency of early diastolic murmurs in isolated defects of the ventricular septum.

I wish to express my thanks to Dr. A. Rae Gilchrist for much help and encouragement in the preparation of this paper and for permission to report Cases 3 and 4 ; to Prof. R. W. B. Ellis for permission to report Case 1 ; to Dr. J. L. Henderson for permission to report Case 2; to Dr. Agnes R. MacGregor for very helpful advice on the postmortem specimens and for permission to go through the necropsy reports of the Royal Hospital for Sick Children, Edinburgh; and to Miss Ann Brown for her beautiful drawings. 


\section{REFERENCES}

Abbott, M. E. (1927). Osler's Modern Medicine, Vol. IV.

(1936). Atlas of Congenital Cardiac Disease. New York. American Heart Association.

Baldwin, E. de F., Moore, L. V., and Noble, R. P. (1946). Amer. Heart J., 32, 152.

Bauer, D. de F., and Astbury, E. C. (1944). Ibid., 27, 688.

Brown, J. W. (1939). Congenital Heart Disease. London. Staples.

Burchell, B. B., Taylor, B. E., Pollack, A. A., DuShane, J. W., and Wood, E. H. (1948). Proc. Mayo Clin., $23,507$.

Dupré, E. (1891). Bull. Soc. Anat., Paris, 5, 404.

East, T. (1937). Proc. Roy. Soc. Med., 30, 696.

Gelfman, R., and Levine, S. A. (1942). Amer. J. med. Sci., 204, 324.

Gilchrist, A. R. (1945). Brit. Heart J., 7, 1. (1948). Edin. med. J., 55, 385.

Griswold, H. E., Bing, R. J., Handelsman, J. C., Campbell, J. A., and LeBrun, E. (1949). Bull. Johns Hopkins Hosp., 84, 76.

Handelsman, J. C., Bing, R. J., Campbell, J. A., and Griswold, H. E. (1948). Ibid., 82, 615.

Laubry, C., and Pezzi, C. (1921). Traité des Maladies Congénitales du Coeur. Paris.

- Routier, D., and Soulié, P. (1933). Rev. Med., Paris, 50, 439.

MacGregor, A. R. (1949). Personal communication.

Muir, D. C., and Brown, J. W. (1934). Arch. Dis. Childh., 9, 27.

Müller, H. (1920). Disch. Arch. klin. Med., 133, 316.

Naish, J., and Wallis, H. R. E. (1948). Brit. med. J., 1, 541.

Perry, C. B. (1937). Proc. Roy. Soc. Med., 30, 693.

Roger, H. (1879). Bull. l'Acad. Roy. Med., 8, 1074.

Selzer, A. (1949). Arch. intern. Med., 84, 798.

Soulié, P., Routier, D., and Bernal, P. (1949). Arch. Mal. Cour., 42, 765.

Taussig, H. B. (1947). Congenital Malformations of the Heart. New York. Commonwealth Fund.

Wilson, F. N., Rosenbaum, F. F., and Johnston, F. D. (1947). Advances in Internal Medicine. New York. Vol. II, p. 41 . 